\title{
Moving from Fossil Fuels to Electric Cooking: An Option for Clean Cooking Access in Nepal
}

\author{
Samikchhya Kafle ${ }^{1, *}$, Arabinda Kumar Mishra ${ }^{1}$, Amina Maharjan ${ }^{1}$, Arnico Kumar Panday ${ }^{1}$ \\ ${ }^{1}$ International Centre for Integrated Mountain Development, Nepal \\ Corresponding Email: Samikchhya.Kafle@icimod.org
}

\begin{abstract}
:
Nepal has abundant hydropower potential and generation capacity under construction that should be able to meet the growing energy need of the country. Although access to electricity in the country is increasing, adoption and access to clean cooking facilities remains insignificant, as about $85 \%$ of the population still rely on solid fuels to meet their daily cooking needs. In this regard, energy generated from hydropower can play the dual role of providing access to modern energy as well as providing a clean cooking alternative that is clean and sustainable. Having realized this, the Ministry of Energy, Water Resources and Irrigation has issued a white paper (point 73) for the 'Electric Stove in Every House' Programme, which is expected to encourage the use of electric cooking. This gives an opportunity not only to make use of Nepal's hydropower resources but also to reduce its dependence on imported fossil fuel. Our paper discusses the challenges and opportunities for introducing electricity in the cooking fuel mix in Nepal from the policy perspective. We draw upon the review of lessons learned from other countries including Ecuador, Bhutan and South Africa, to illustrate the potential pathways for the transition of fossil fuel-based products to electricity in Nepal. These countries have used a combination of approaches in including electricity in their cooking fuel mix, such as favourable electricity pricing, import tariff reductions in cooking appliances, and developing national policy and programmes to facilitate the integration of electricity in cooking fuel. These lessons from these countries are used to recommend pathways for moving from fossil fuel-based products to electricity in Nepal's context.
\end{abstract}

Keywords: Solid Fuel, Cooking Fuel Mix, White Paper, Fossil Fuel

\section{Introduction}

Energy transition theory suggests that, with economic growth, households transition from solid fuels to modern fuels such as kerosene LPG and electricity [1]. However, in countries with geographical constraints and remote rural areas, the theory may not fully hold true. Topographical factors together with limited transport infrastructure may impede the regular supply of modern fuels and also make them more expensive, thus depriving the communities of desired access and usage. As a result, households might continue to use solid fuels to meet their daily cooking needs due to its easy availability and low cost. A study by [2] has pointed out that price and availability of fuels is one of the major demand factors that influence fuel choice. For mountain communities with limited access to regular fuel supply, several variables besides household income might impede their transition to cleaner fuels.

Nepal is a mountainous country. More than $80 \%$ of the area is covered by hills and mountains. The per capita annual energy consumption was $14.32 \mathrm{GJ}$ in 2010 [3], whereas the global average was 77GJ [4]. The residential sector accounts for more than $80 \%$ of the total energy consumption, out of which $49 \%$ is consumed for cooking. More than $85 \%$ of residential cooking energy needs are met through solid fuels while the rest is met by modern fuels such as LPG, biogas, kerosene and electricity. Solid fuel is the primary fuel for cooking in rural areas while LPG is the most used fuel type, followed by solid fuels in urban areas [5]. In Nepal, access to both electricity and clean cooking fuel has almost tripled between 2000 and 2010 and is increasing still; however, there is a lot of room for improving access to clean cooking [6].

As seen in Figure 1, 85\% of the total population had access to electricity in 2014 , whereas only $26 \%$ had access to clean cooking facilities. Electricity access is growing in both urban and rural areas. In this context, electricity as an additional option in the cooking fuel mix should be considered as an opportunity to meet the dual target of providing access to modern energy as well as providing a clean cooking alternative.

Nepal has abundant hydropower potential; it is estimated to be around $84,000 \mathrm{MW}$, out of which $43,000 \mathrm{MW}$ is economically viable. The large hydropower potential and generation capacity under construction should be able to 


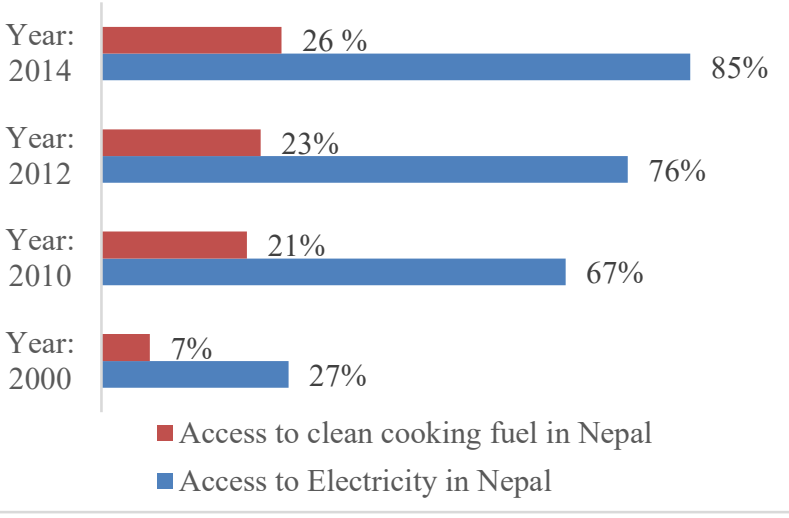

Figure 1: Comparison of access to electricity and clean cooking facilities in Nepal [6]

meet the growing energy need of the country [7]. Countries with abundant hydropower potential such as Ecuador, Bhutan and some parts of India such as Himachal Pradesh have successfully incorporated electricity as a clean fuel for cooking [8-10]. 'The dominance of and reliance on a single fuel source has seriously hindered Nepal's ability to meet energy needs during times of crisis. Thus, the aadoption of domestically available, sustainable and clean cooking fuel sources would help to overcome this challenge. Having realized this, the Ministry of Energy, Water Resources and Irrigation has issued a white paper (point 73) for the 'Electric Stove in Every House' Programme with the aim to increase the adoption of electricity for cooking in both urban and rural households in Nepal. This point is also consistent with many of the government's objectives such as NEA's objective of achieving energy security and demand-side management with an energy efficiency programme [11], and MoPE's goal of making Nepal indoor air pollution free by 2022 through the use of clean cooking technologies in all households; and by 2030, ensuring the availability of modern clean energy in all the households previously using solid biomass [12].

\section{Favorable policies for the transition from fossil fuel to electricity-based cooking}

Studies from other countries that have integrated electricity as a cooking fuel show that effective policy formulation enables the transition towards electric cooking. Policies and programmes should take into consideration the advantages of domestic production of hydroelectricity and renewable energy and its role in reducing the import of fossil fuels. Policies that have been introduced to integrate electricity as a clean cooking fuel in the cooking fuel mix are analyzed below.

\subsection{Electricity tariff rate}

Studies have shown that subsidized electricity has enabled the transition towards electric cooking [13-15]. Countries like South Africa, Ecuador, and Bhutan, where electricity is now widely used for cooking, have adopted the policy of subsidized electricity tariff. Electricity is more expensive than traditional fuels, so households rely on cheaper and readily available alternatives such as solid fuels or coal for cooking and heating [16]. Subsidizing electricity can make electricity a competitive alternative to other energy sources such as solid fuels.

In South Africa, the government introduced a Free Basic Electricity (FBE) scheme that offered 50-kilowatt hours $(\mathrm{kWh})$ per month for free to most households with access to electricity. The aim was to provide low-income households with electricity to support basic lighting, the use of an electric kettle for boiling water, basic ironing, and the use of a small black-and-white television. After the implementation of the FBE scheme, the average monthly electric consumption of low-income households increased from about $20 \mathrm{kWh}$ to $35 \mathrm{kWh}$ [13]. A survey by the University of Cape Town in Khayelitsha Township also showed that households started using electric cookers and electricity for bulk heating of water after they started receiving free electricity [17].

Electricity is subsidized in Bhutan. Rural households used to pay Ngultrum 0.85 per $\mathrm{kWh}$ for consumption below $100 \mathrm{kWh}$. Bhutan's 'free power implementation programme' (2013-2016) provided $100 \mathrm{kWh}$ of free electricity to rural households. A total of 77,030 rural households benefitted from this programme. Even after the completion of the programme, low-voltage consumers in rural areas were provided 100 free units of electricity for domestic use. Consumers under this scheme included locals, small shops and monasteries. Electricity could be accessed for a maximum for 3 hours per day and could support the use of 20-watt fluorescent light bulbs, water boilers, rice cookers, curry cookers and TV [10].

\subsection{The cost of electric stoves}

Studies have shown that government policies also help in promoting electric stoves because the cost of electric stoves has a direct impact on consumers' choice [18]. In countries where electricity has widely been adopted for cooking, consumers have received support from the government through tariff exemption for electric cooking appliances. In several countries including Bhutan, Ecuador and South Africa, government policies have supported the uptake of electric stoves. In Bhutan, policies encourage the use of wood-saving appliances such as rice 
cookers, water boilers, curry cookers, etc. Government policy that allows duty-free import of fuelwood saving appliances has shifted consumers' choice from fuelwood to other clean cooking options [19]. In South Africa, government policy supported the use of electric stoves and made the price of electric stoves lower than that of gas stoves [13].

The policies to encourages electric cooking should pay attention to regular electric supply, cost of electric appliances that enables consumers to choose electric cooking appliances. In China and India, the availability of reliable electricity has not only increased the popularity of low-cost electric appliances like water kettles and microwaves but also increased the demand for electric cooking devices that are especially designed for preparing local foods such as pancake and roti [8].

\subsection{Government policy and programmes to encourage electric cooking}

Government policies and programmes also play an important role in the transition towards electric cooking. Governments often have different reasons for promoting electric cooking -reducing risks, import substitution, promoting clean development, etc. In South Africa, one of the objectives behind promoting electric cooking was to avoid the high risk of fire posed by paraffin stoves. This led the government to adopt a policy that favours electric cooking $[18,20]$. The Government of Ecuador introduced the National Efficient Cooking Programme (NECP) with an aim to replace 3 million existing gas stoves with induction stoves $[8,15]$. The NECP sought to promote electricity as the primary source of cooking fuel at the national level in order to bring positive changes in the national energy matrix and reduce dependence on LPG. In Bhutan, promotion of electric cooking is included in the government's goal of achieving low carbon development by 2022 [19]. Bhutan aims to reduce deforestation through the promotion of electric cooking.

\section{Potential ways for transitioning to electric cooking in Nepal}

Based on the learning from other countries, this section outlines policy measures and programmes that can help Nepal to transition from LPG to electric cooking

in urban areas and solid fuels to electricity in rural areas. The various policies and key recommendations are provided in Table 1.

\section{Conclusion}

Nepal has abundant hydropower potential to meet the growing energy need. Electricity generated from hydropower is clean, sustainable and environmentfriendly. In this regard, providing clean cooking facilities to both rural and urban areas through electricity could play a major role in reducing indoor emissions and transitioning to domestically available and modern fuel. In Nepal, both rural and urban areas rely heavily on solid

Table 1: Favourable policy drivers for transitioning to electric cooking in Nepal with potential pathways

\begin{tabular}{|c|c|}
\hline Policies & Key recommendations \\
\hline \multirow[b]{2}{*}{ Electricity tariff rate } & Subsidizing electricity in rural households with an aim to provide clean access to cooking and lighting. \\
\hline & $\begin{array}{l}\text { Reviving old and abandoned micro-hydro plants and using them for cooking purposes in areas that are } \\
\text { already connected to the national grid. }\end{array}$ \\
\hline Cost of electric stoves & $\begin{array}{l}\text { Reviewing current import duties, i.e., } 7.5 \% \text { if manufactured in SAARC countries and } 13 \% \text { if outside } \\
\text { SAARC countries, with an additional } 13 \% \text { VAT [21]. }\end{array}$ \\
\hline \multirow{7}{*}{$\begin{array}{l}\text { Government policy and } \\
\text { programmes to encourage } \\
\text { electric cooking }\end{array}$} & Incorporating electric cooking in energy planning and infrastructure design. \\
\hline & $\begin{array}{l}\text { Integrating electricity as a cooking fuel in the national strategy to meet targets such as providing access } \\
\text { to clean cooking in order to achieve the national goal of providing smoke-free kitchens by } 2030 \text { and the } \\
\text { international commitment to achieve SDG } 7 \text {. }\end{array}$ \\
\hline & Promoting electric cooking for demand side management [11] \\
\hline & $\begin{array}{l}\text { Using different national media platforms to showcase the benefits of electric cooking over biomass and } \\
\text { fossil fuel-based cooking. }\end{array}$ \\
\hline & Incorporating electric cooking in feasibility studies of small-scale hydro \\
\hline & $\begin{array}{l}\text { Coordinating and monitoring the electric cooking sector by a government body including the standard } \\
\text { of the stove, cooking utensils, etc. }\end{array}$ \\
\hline & $\begin{array}{l}\text { Quicker transition from traditional to modern fuels for cooking can be achieved by coupling a subsidy } \\
\text { policy with availability of easy credit [22]. }\end{array}$ \\
\hline
\end{tabular}


fuels for cooking. An estimated $68 \%$ of the urban areas rely on LPG, followed by biomass. In rural areas, almost $90 \%$ of the population depends on solid fuels. The penetration of electricity is growing in both urban and rural areas. This has provided Nepal the opportunity to transition from LPG/solid fuels to electricity. Because of the difficult topography in the hills/mountains and the rural/urban divide, many communities in Nepal have limited access to clean energy technology. Therefore, different kinds of electric cooking appliances need to be proposed according to available infrastructure. In urban centres with reliable electricity supply, induction cook stoves could be most appropriate whereas in rural areas with limited electric supply, e-cook, curry cookers or lower wattage cooking appliances could be useful. With proper policy, programmes and access to technology, there is a huge opportunity for people to switch to modern sources of energy like electricity for cooking. This will help reduce negative health impacts of solid fuel cooking, improve livelihood as well as ensure energy security in the long run.

\section{References}

[1] G. Leach, "The energy transition," Energy Policy, vol. 20, no. 2, pp. 116-123, 1992.

[2] G. Leach and M. Gowen, Household energy handbook: an interim guide and reference manual., no. 67. 1987.

[3] WECS, "Energy Sector Synopsis Report," 2010.

[4] IEA, "Renewables Information Edition,” Paris, 2010.

[5] Central Bureau of Statistics, "National population and housing census 2011," 2012.

[6] IEA \& World Bank, "Sustainable Energy for All 2017Progress toward Sustainable Energy" (Summary)," Washington, DC., 2017.

[7] NEA, “A Year in Review: Fiscal Year 2017/18," 2018.

[8] K. R. Smith and A. Sagar, "Making the clean available: Escaping India's Chulha Trap,” Energy Policy, vol. 75, pp. 410-414, 2014.

[9] J. Martínez-Gómez, D. Ibarra, S. Villacis, P. Cuji, and P. R. Cruz, "Analysis of LPG, electric and induction cookers during cooking typical Ecuadorian dishes into the national efficient cooking program," Food Policy, vol. 59, pp. 88$102,2016$.

[10] D. Yangka and M. Diesendorf, "Modeling the benefits of electric cooking in Bhutan: A long term perspective," Renewable and Sustainable Energy Reviews, vol. 59. pp. 494-503, 2016.

[11] NEA, “A Year in Review: Fiscal Year 2016/17,” 2017.
[12] MoPE, "Renewable Energy Subsidy Policy, 2073 BS," 2016.

[13] M. Howells, D. G. Victor, T. Gaunt, R. J. Elias, and T. Alfstad, "Beyond free electricity: The costs of electric cooking in poor households and a market-friendly alternative," Energy Policy, vol. 34, no. 17, pp. 33513358, 2006.

[14] D. B. Rahut, S. Das, H. De Groote, and B. Behera, "Determinants of household energy use in Bhutan," Energy, vol. 69, pp. 661-672, 2014.

[15] J. Martínez, J. Martí-Herrero, S. Villacís, A. J. Riofrio, and D. Vaca, "Analysis of energy, CO2emissions and economy of the technological migration for clean cooking in Ecuador," Energy Policy, vol. 107, pp. 182-187, 2017.

[16] A. Williams, A. Eberhard, and B. Dickson, "Synthesis report of the Biomass Initiative," Pretoria, Chief Dir. Energy. Dep. Miner. Energy Aff., 1996.

[17] W. Cowan and N. Mohlakoana, "Income Related Aspects of Energy Use," in Workshop on Energy Transitions, Cape Town, 2004, pp. 18-20.

[18] B. Cowan, "Identification and Demonstration of Selected Energy Best Practices for Low-Income Urban Communitites in South Africa," Alleviation Poverty through Provis. Local Energy Serv. (APPLES). Proj. No. EIE-04-168. Deliv. No, vol. 17, 2008.

[19] DoE, "Overview of Energy Policies of Bhutan.' Department of Energy,Ministry of Economic Affairs Thimphu, Bhutan:, 2009.

[20] B. Bekker, A. Eberhard, T. Gaunt, and A. Marquard, "South Africa's rapid electrification programme: Policy, institutional, planning, financing and technical innovations," Energy Policy, vol. 36, no. 8, pp. 31253137, 2008 .

[21] Ministry of Finance, “Customs Tariff 2017/2018,” 2017.

[22] T. Ekholm, V. Krey, S. Pachauri, and K. Riahi, "Determinants of household energy consumption in India," Energy Policy, vol. 38, no. 10, pp. 5696-5707, 2010. 